\title{
Evaluasi Usability Google Classroom Menggunakan System Usability Scale
}

\author{
Dimas Setiawan ${ }^{1}$, Suluh Langgeng Wicaksono ${ }^{2}$ \\ 12 Universitas PGRI Madiun \\ dimas.is.my.name@gmail.com ${ }^{1}$, suluh.langgeng@gmail.com ${ }^{2}$
}

\begin{abstract}
In this Covid-19 pandemic, E-learning users have been increased, WFH (work from home) policy make the whole process of learning activities in the Universitas PGRI Madiun has been replaced by an online learning model. One of the E-Learning platforms that is widely used by Google Classroom, as one of the most widely used platforms, of course, needs to be evaluated for satisfaction so that there are improvements in the future. System Usability Scale is one of the Usability evaluation methods can be applied in a digital product like an E-learning platform. this Evaluation method has been doing to several participants especially college students in the Department of Information Technology and information system's UNIPMA. The evaluation results of the Google Classroom Usability E-learning platform has a score of 82.8 points of Usability.
\end{abstract}

Keyword : Usability, E-Learning, Google Classsroom, Moodle, System Usability Scale

\begin{abstract}
Abstrak
Pandemi Covid-19 membuat pengguna E-learning di masa meningkat pesat, hal ini dikarenakan adanya kebijakan WFH (work from home) dari pemerintah sehingga seluruh proses kegiatan pembelajaran di kelas digantikan dengan model pembelajaran secara online, tak tekecuali di Universitas PGRI Madiun. Salah satu platform E-Learning yang banyak digunakan adalah Google Classroom, sebagai salah satu platform yang banyak digunakan tentunya perlu dilakukan evaluasi kepuasan agar terdapat perbaikan kedepannya. System Usability Scale merupakan salah satu metode evaluasi yang digunakan untuk melihat usabilitas dari sebuah produk perangkat lunak. Evaluasi Usability ini dilakukan kepada 10 responden pengguna Google clasrrom mahasiswa lintas angkatan, khususnya di program studi sistem informasi dan Teknik informatika UNIPMA. Berdasarkan hasil evaluasi Usability E-learning platform Google calssroom memiliki score 82,8 dan dianggap telah memenuhi unsur Usablity .
\end{abstract}

Kata Kunci: Usability, E-Learning, Google Classsroom, Moodle, System Usability Scale

ISSN 2715-0143 (online) ISSN 2714-9048 (print)

http://journal.walisongo.ac.id/index.php/jit/ind

WJIT : Walisongo Journal of Information Technology - Vol. 2 No. 1 (2020) 


\section{PENDAHULUAN}

Studi tentang pembelajaran online merupakan topik yang populer dan hangat untuk dibicarakan (Sujito, Arifudin, \& Arini, 2019), apalagi pengguna E-learning di masa Pandemi Covid-19 meningkat pesat, hal ini dikarenakan adanya kebijakan WFH (work from home) dari pemerintah sehingga seluruh proses kegiatan pembelajaran di kelas digantikan dengan model pembelajaran secara online atau pendidikan Jarak Jauh (PJJ) (Rusdiana, Sulhan, Zaenal, \& Ahmad, 2020). Selain itu trend dari teknologi pendidikan juga mengarah ke teknologi pembelajaran bersifat online, mobile, multimedia(Setiawan \& Noordin Asnawi, 2017). Dalam kegiatan pembelajaran online salah satu platform E-Learning yang banyak digunakan Google Classroom.

Sebagai upaya untuk mendukung proses pembelajaran secara online serta mewujudkan ekosistem smart campus, Universitas PGRI Madiun (UNIPMA) berupaya memaksimalkan penggunaa teknologi dan sistem informasi di lingkungan kampus (Setiawan, 2019). E-learning yang digunakan setidaknya dapat memanfaatkan Moodle sebagai Learning Management System nya, hal ini sejalan dengan hasil analisa kebutuhan e-learning dimana materi dan fasilitas ujian bisa dilaksanakan secara daring, menggunakan teknologi informasi terbaru, memiliki UI yang baik, sistem keamanan, forum diskusi ilmiah serta memperhatikan Learning Management System, knowledge managemenent, dan knowledge transfer. (Setiawan, 2018).
Walaupun Google Classroom tidak memiliki beberapa unsur standar Elearning di atas namun pada praktiknya banyak digunakan untuk mendukung kegiatan pembelajaran secara online.

Dalam prosesnya terdapat beberapa kendala dimana pengguna baik mahasiswa maupun dosen masing-masing tentunya merasa memiliki kesulitan tersendiri ketika mengoperasikan platform ini, bahkan tak jarang memunculkan konflik dan perbedaan pendapat mengenai platform e-learning manakah yang lebih mudah dan lebih baik untuk digunakan.

Berdasarkan permasalahan tersebut maka diperlukan sebuah evaluasi usability terhadap platform E-learning ini. Istilah usability disebutkan pertama kali pada ISO 9241-11 (1998) yang menjelaskan bahwa usability menunjuk pada tingkat sebuah produk yang dapat digunakan oleh pengguna tertentu untuk mencapai tujuan spesifik dengan efektif (effectiveness), efisien (efficiency), dan memuaskan (statisfaction) dalam sebuah konteks penggunaan(Kaya, Ozturk, \& Gumussoy, 2020). Pengukuran terhadap usability diperlukan untuk meningkatkan pengalaman pengguna. (Finstad, 2010). Selain itu usability berfungsi untuk mengukur tingkat kepuasan pengguna terhadap sebuah produk (Taylor et al., 2015)

Di dalam ilmu User Experience terdapat pembahasan mengenai pengukuran tingkat usability, yaitu kegiatan untuk mengevaluasi kemudahan suatu produk yang sudah 
Evaluasi Usability Google Classroom Menggunakan System Usability Scale

dibuat dengan melihat dari beberapa aspek dari kepuasan pengguna. Salah satu Evaluasi Usability yang bisa dilakukan adalah dengan menggunakan System Usability Scale (SUS). SUS merupakan salah satu metode evaluasi yang digunakan untuk melihat usabilitas dari sebuah produk perangkat lunak. Tidak hanya perangkat lunak, SUS juga dapat digunakan untuk mengukur tingkat penerimaan siswa terhadap berbagai macam model teknologi pembelajaran(Revythi \& Tselios, 2019) Diharapkan dengan adanya evaluasi ini dapat diketahui tingkat usabilitas dari Google Classroom sehingga dari hasil yang didapatkan dapat digunakan untuk bahan perbaikan kedepannya.

\section{METODE}

Penelitian ini menggunakan metode penelitian Kuantitatif, dimana terdapat analisa data kuantitatif terhadap pengukuran tingkat usability Google Classrom menggunakan System Usability Scale / SUS Questionnaire.

Jumlah responden pada penelitian ini sebanyak 10 orang mahasiswa aktif lintas angkatan dari program studi sistem informasi dan teknologi informatika Universitas PGRI Madiun. Adapun teknisnya 10 responden akan diberikan SUS Questionnaire untuk platform Google Classroom

Secara keseluruhan alur dari penelitian ini sebagai berikut :

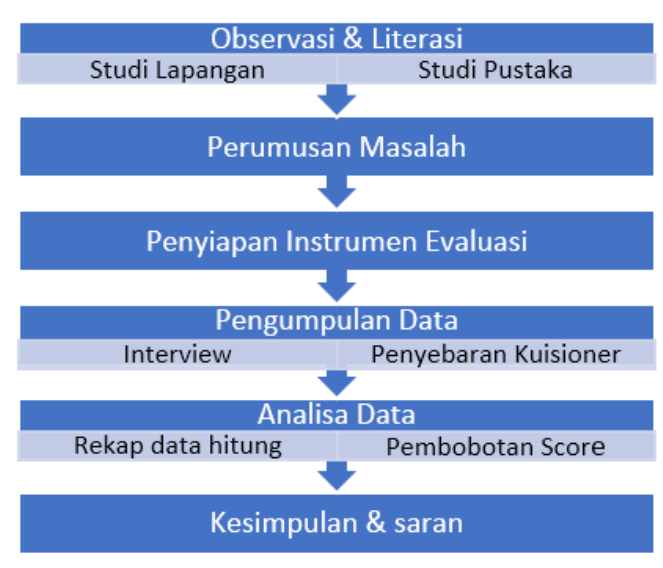

Gambar .1 flowchart penelitian

\section{KERANGKA TEORI}

\subsection{E-Learning}

E-learning adalah kegiatan pembelajaran konvensional yang dituangkan kedalam format digital dengan memanfaatkan teknologi komputer dan internet sebagai media \& sumber ajar.(Setiawan \& Noordin Asnawi, 2017)

E-learning merupakan VLE (virtual learning environment) yang mana di era sekarang banyak cara dilakukan untuk diuji coba kefektifasannya. (Hayashi, Chen, Ryan, \& Wu, 2020),

E learning sendiri memiliki dua macam model yaitu synchronous dan asynchronous. Dimana pada synchronous, siswa dan pengajar bertemu dalam satu waktu dan melakukan proses pembelajaran secara langsung meski dalam proses online. Namun pada asynchronous, siswa hanya perlu mengakses materi ajar yang sudah tersedia pada paltform yang sudah disediakan dan dapat diakses sewaktu waktu tanpa perlu melakukan tatap muka dan 
melakukan janji temu dengan pengajar. (Setiawan, 2018) Berdasarkan

bentuk kurikulumnya, E-learning sendiri juga terbagi menjadi 3 kelompok, yaitu:

1. Formal e-learning platform

E-learning ini memiliki karakteristik terdapat Konten, tujuan pembelajaran, modul, waktu terbatas, kontak pengajar, kegiatan dan penilaian pembelajaran yang formal.

2. Informal e-learning platform

E-learning ini memiliki karakteristik Konten, penilaian hasil belajar, serta sumber dan waktu belajar felksibel dan tanpa batas, dimana siswa bisa mengakses kapanpun dia mau.

3. Non-formal e-learning platform

E-learning ini memiliki Konten, tujuan, waktu dan kegiatan yang lebih mengarah pada kebutuhan pribadi. (Mpungose, 2020)

\subsection{Google Classroom}

Google Classroom adalah aplikasi layanan pembelajaran yang dapat diakses secara gratis untuk keperluan akademik dan organisasi nirlaba. Siapa pun dapat mengakses fitur Google Clasrrom selama meraka memiliki akun google. Google Classroom sendiri dapat diakses secara multiplatform baik menggunakan komputer dekstop maupun perangkat yang bersifat mobile seperti nootebook ataupun smatphone, dan mampu berjalan di beberapa sistem operasi seperti android, ios, windows dan lain sebagainya (Ni, 2020)
Berikut adlaah beberapa Fitur utama dari Google Classroom diantarnya:

1. Assignment (task)

Tugas disimpan dan diberi peringkat dalam serangkaian aplikasi produktivitas Google, memungkinkan kolaborasi antara guru dan siswa.

2. Rating (measurement)

Google Classroom mendukung banyak hal skema penilaian yang berbeda. Guru dapat memilih untuk melampirkan file ke tugas di mana siswa dapat melihat, mengedit, atau mendapatkan satu salinan.

3. Communication

Guru dapat memasang buletin di jalan aliran, dan mahasiswa dapat memberikan komentar itu memungkinkan pertukaran verbal dua arah antara guru dan siswa.

\subsection{System Usability Scale}

Secara teknis SUS memiliki 10 item pertanyaan yang dikemas dalam bentuk kuisioner, tetapi dalam pengembangannya bisa dimungkinkan dibuat dalam bentuk gambar yang dinamakan Pictorial-SUS (Baumgartner, Frei, Kleinke, \& Sauer, 2019)

System Usability Scale (SUS) memiliki 10 item pernyataan, 5 point skala likert dengan pilihan respon dari "Strongly disagree" hingga "Strongly Agree", dan pembobotan score antara 0-100. Tabel 1. dan tabel 2 . merupakan contoh dari 10 item pernyataan yang ada pada System Usablity Scale Questionnaire. 
Evaluasi Usability Google Classroom Menggunakan System Usability Scale

Tabel 1

10 item pertanyaan SUS Questionnaire

\begin{tabular}{|l|l|c|c|c|c|c|}
\hline & \multicolumn{1}{|l}{$\begin{array}{l}\text { Strongly } \\
\text { Disagree }\end{array}$} & & & $\begin{array}{l}\text { Strongly } \\
\text { Agree }\end{array}$ \\
\hline $\mathbf{1}$ & $\begin{array}{l}\text { I think that I would like to use Google Classroom } \\
\text { frequently. }\end{array}$ & 1 & 2 & 3 & 4 & 5 \\
\hline $\mathbf{2}$ & Ifound Google Classroom unnecessarily complex. & 1 & 2 & 3 & 4 & 5 \\
\hline $\mathbf{3}$ & I thought Google Classroom was easy to use. & 1 & 2 & 3 & 4 & 5 \\
\hline $\mathbf{4}$ & $\begin{array}{l}\text { I think that I would need the support of a } \\
\text { technical person to be able to use Google } \\
\text { Classroom. }\end{array}$ & 1 & 2 & 3 & 4 & 5 \\
\hline $\mathbf{5}$ & $\begin{array}{l}\text { I found the various functions in Google Classroom } \\
\text { were well integrated. }\end{array}$ & 1 & 2 & 3 & 4 & 5 \\
\hline $\mathbf{6}$ & $\begin{array}{l}\text { I thought there was too much inconsistency in } \\
\text { Google Classroom. }\end{array}$ & 1 & 2 & 3 & 4 & 5 \\
\hline $\mathbf{7}$ & $\begin{array}{l}\text { I would imagine that most people would learn to } \\
\text { use Google Classroom very quickly }\end{array}$ & 1 & 2 & 3 & 4 & 5 \\
\hline $\mathbf{8}$ & $\begin{array}{l}\text { I found Google Classroom very cumbersome } \\
\text { (awkward) to use. }\end{array}$ & 1 & 2 & 3 & 4 & 5 \\
\hline $\mathbf{9}$ & Ifelt very confident using Google Classroom. & 1 & 2 & 3 & 4 & 5 \\
\hline $\mathbf{1 0}$ & $\begin{array}{l}\text { I needed to learn a lot of things before I could get } \\
\text { going with Google Classroom }\end{array}$ & 1 & 2 & 3 & 4 & 5 \\
\hline
\end{tabular}

Pembobotan SUS Score yang dibagi menjadi 5 Letter Grade dari $A, B, C, D$, dan $F$ dengan pilihan rating
Excellent, Good, OK, Poor, dan Awful. Berikut rinciannya :

Tabel 2

Pembobotan score SUS Questionnaire

\begin{tabular}{|l|l|l|}
\hline SUS Score & Letter Grade & Adjective Rating \\
\hline Above 80.3 & A & Excellent \\
\hline Between $\mathbf{6 8}$ and $\mathbf{8 0 . 3}$ & B & Good \\
\hline $\mathbf{6 8}$ & C & OK \\
\hline Between $\mathbf{5 1}$ and $\mathbf{6 7}$ & D & Poor \\
\hline Below 51 & F & Awful \\
\hline
\end{tabular}

\section{PEMBAHASAN}

Pada penelitian ini hanya digunakan kuisioner tanpa melibatkan Pictoria-SUS. Untuk pembuatan System Usability Scale Questionnaire, tools yang digunakan adalah SUS PDF generator, yang bisa diakses pada 
https://www.usabilitest.com/suspdf-generator.

Hal ini mempermudah dalam penyusuan SUS Questionnaire. Untuk pengolahan data digunakan perangkat lunak Microsoft Excell, dan untuk pengumpulan instrumen sebagian juga menggunakan Google Form guna mempermudah pendistribusian SUS Questionnaire. Setelah melakukan penyeberan SUS Kuisioner ke 10 responden didapat data asli sebagai berikut :

Tabel 2

Data asli SUS Questionnaire untuk Google Classroom

\begin{tabular}{|c|c|c|c|c|c|c|c|c|c|c|c|}
\hline No & Responden & \multicolumn{10}{|c|}{ Skor Asli penilaian Google Classroom } \\
\cline { 3 - 13 } & & Q1 & Q2 & Q3 & Q4 & Q5 & Q6 & Q7 & Q8 & Q9 & Q10 \\
\hline 1 & R1 & 4 & 1 & 4 & 1 & 5 & 2 & 5 & 2 & 5 & 2 \\
\hline $\mathbf{2}$ & R2 & 4 & 1 & 5 & 2 & 4 & 2 & 5 & 2 & 4 & 2 \\
\hline $\mathbf{3}$ & R3 & 4 & 1 & 5 & 1 & 5 & 3 & 5 & 2 & 5 & 2 \\
\hline $\mathbf{4}$ & R4 & 4 & 2 & 4 & 2 & 5 & 1 & 5 & 2 & 4 & 2 \\
\hline $\mathbf{5}$ & R5 & 4 & 2 & 5 & 2 & 5 & 1 & 4 & 2 & 4 & 2 \\
\hline $\mathbf{6}$ & R6 & 5 & 1 & 5 & 2 & 4 & 1 & 4 & 2 & 5 & 2 \\
\hline $\mathbf{7}$ & R7 & 3 & 2 & 4 & 2 & 5 & 2 & 5 & 2 & 4 & 2 \\
\hline $\mathbf{8}$ & R8 & 5 & 2 & 5 & 2 & 5 & 3 & 5 & 2 & 5 & 2 \\
\hline $\mathbf{9}$ & R9 & 3 & 2 & 4 & 2 & 5 & 2 & 4 & 2 & 4 & 2 \\
\hline $\mathbf{1 0}$ & R10 & 5 & 2 & 5 & 2 & 4 & 2 & 4 & 2 & 4 & 2 \\
\hline
\end{tabular}

Data tersebut nantinya akan dihitung untuk diberikan pembobotan SUS score. Namun terdapat aturan dalam menghitung SUS score Berikut ini aturan-aturan saat perhitungan skor pada kuesionernya:

1. Setiap pertanyaan bernomor ganjil, score akhirnya merupakan hasil pengurangan score pengguna $(\mathrm{x})$ dikurangi 1 .

2. Setiap pertanyaan bernomor genap, score akhirnya didapat

Tabel 3

Data Hitung SUS Questionnaire untuk Google Classroom

\begin{tabular}{|c|c|c|c|c|c|c|c|c|c|c|c|c|c|}
\hline \multirow[t]{2}{*}{ No } & \multirow[t]{2}{*}{ Responden } & \multicolumn{10}{|c|}{ Skor hasil Hitung penilaian Google Classroom } & \multirow{2}{*}{$\begin{array}{c}\text { Jumlah } \\
\text { JML }\end{array}$} & \multirow{2}{*}{$\begin{array}{c}\text { Nilai } \\
\text { JML*2,5 }\end{array}$} \\
\hline & & Q1 & Q2 & Q3 & Q4 & Q5 & Q6 & Q7 & Q8 & Q9 & Q10 & & \\
\hline 1 & R1 & 3 & 4 & 3 & 4 & 4 & 3 & 4 & 3 & 4 & 3 & 35 & 88 \\
\hline 2 & R2 & 3 & 4 & 4 & 3 & 3 & 3 & 4 & 3 & 3 & 3 & 33 & 83 \\
\hline 3 & R3 & 3 & 4 & 4 & 4 & 4 & 2 & 4 & 3 & 4 & 3 & 35 & 88 \\
\hline 4 & R4 & 3 & 3 & 3 & 3 & 4 & 4 & 4 & 3 & 3 & 3 & 33 & 83 \\
\hline
\end{tabular}


Evaluasi Usability Google Classroom Menggunakan System Usability Scale

\begin{tabular}{|c|c|c|c|c|c|c|c|c|c|c|c|c|c|}
\hline $\mathbf{5}$ & R5 & 3 & 3 & 4 & 3 & 4 & 4 & 3 & 3 & 3 & 3 & 33 & 83 \\
\hline $\mathbf{6}$ & R6 & 4 & 4 & 4 & 3 & 3 & 4 & 3 & 3 & 4 & 3 & 35 & 88 \\
\hline $\mathbf{7}$ & R7 & 2 & 3 & 3 & 3 & 4 & 3 & 4 & 3 & 3 & 3 & 31 & 78 \\
\hline $\mathbf{8}$ & R8 & 4 & 3 & 4 & 3 & 4 & 2 & 4 & 3 & 4 & 3 & 34 & 85 \\
\hline $\mathbf{9}$ & R9 & 2 & 3 & 3 & 3 & 4 & 3 & 3 & 3 & 3 & 3 & 30 & 75 \\
\hline 10 & R10 & 4 & 3 & 4 & 3 & 3 & 3 & 3 & 3 & 3 & 3 & 32 & 80 \\
\hline \multicolumn{110}{|c|}{ Jumlah pkada Google Classroom } \\
\hline
\end{tabular}

Untuk perhitungan selanjutnya, SUS score dari masing masing responden dicari score rata ratanya dengan cara menjumlahkan keseluruhan score dan dibagi dengan jumlah responden, berikut rumusnya:

$$
\begin{array}{llrl}
\bar{x}^{-} & & & \text {skor rata-rata } \\
\sum x= & & \text { jumlah skor SUS } \\
n & = & & \text { jumlah responden }
\end{array}
$$

Grafik.1 Rumus hitung SUS score

Dari hasil perhitungan diatas didapat skor rata rata untuk Platform Google Classroom sebesar 82,8. dengan rating "Excellent" dan Letter Grade "A".

Dari kuisioner yang diberikan terdapat saran untuk perbaikan untuk Google classroom perlu penambahan tombol fitur "live conference" untuk melengkapi fiturnya, attachment beberpa video pembelajaran, yang langsung bisa diakses di dalam classroom.

\section{PENUTUP}

Berdasarkan hasil evaluasi Usability menggunakan SUS Questionnaire terhadap 10 responden mahasiswa aktif lintas angkatan platform Google Classroom sebesar 82,8. dengan rating "Excellent" dan Letter Grade " $A$ ". dari hasil ini didapati google calssroom sudah memenuhi unsur Usablity , namun terdapat saran untuk perbaikan untuk Google classroom perlu penambahan tombol fitur "live conference" untuk melengkapi fiturnya, attachment beberpa video pembelajaran, yang langsung bisa diakses di dalam classroom. 


\section{REFERENCES}

Baumgartner, J., Frei, N., Kleinke, M., \& Sauer, J. (2019). Pictorial System Usability Scale ( P-SUS ): Developing an Instrument for Measuring Perceived Usability, 111.

Finstad, K. (2010). Interacting with Computers The Usability Metric for User Experience. Interacting with Computers, 22(5), 323-327. https://doi.org/10.1016/j.intcom.2010.04.004

Hayashi, A., Chen, C., Ryan, T., \& Wu, J. (2020). The Role of Social Presence and Moderating Role of Computer Self Efficacy in Predicting the Continuance Usage of E-Learning Systems. Journal of Information Systems Education, 15(2), 5.

Kaya, A., Ozturk, R., \& Gumussoy, C. A. (2020). Usability Measurement of Mobile Applications with System Usability Scale ( SUS ).

Mpungose, C. B. (2020). Is Moodle or WhatsApp the preferred e-learning platform at a South African university? First-year students' experiences. Education and Information Technologies, 25(2), 927-941. https://doi.org/10.1007/s10639019-10005-5

Ni, L. B. (2020). Blended Learning through Google Classroom, 14(4), 220-226.

Revythi, A., \& Tselios, N. (2019). Extension of technology acceptance model by using system usability scale to assess behavioral intention to use e-learning.

Rusdiana, A., Sulhan, M., Zaenal, I., \& Ahmad, A. U. (2020). Penerapan Model POE2WE Berbasis Blended Learning Google Classroom Pada Pembelajaran Masa WFH Pandemic Covid-19, 1-10.

Setiawan, D. (2018). ANALISIS KEBUTUHAN E-LEARNING PROGRAM STUDI SISTEM INFORMASI UNIVERSITAS PGRI MADIUN. SENATIK, 30-36.

Setiawan, D. (2019). Analisis Dan Perancangan Sistem Informasi LENTERA Untuk Membentuk "Smart Society" Di Lingkungan Kampus Menggunakan Metode OOAD ( Studi Kasus : Universitas PGRI Madiun ), 155-159.

Setiawan, D., \& Noordin Asnawi, H. A. M. (2017). LECTURERS INFORMATICS ENGINEERING STUDY PROGRAM, (Icons), 1168-1173.

Sujito, F., Arifudin, R., \& Arini, F. Y. (2019). An Analysis of User Interface and User Experience Using System Usability Scale and GOMS Method, 1(October), 65-73.

Taylor, P., Borsci, S., Federici, S., Bacci, S., Gnaldi, M., Bartolucci, F., ... Bartolucci, F. (2015). International Journal of Human-Computer Interaction Assessing User Satisfaction in the Era of User Experience : Comparison of the SUS , UMUX, and UMUX- LITE as a Function of Product Experience Assessing User Satisfaction in the Era of User Experience : C, (August). 